\title{
Microleakage in Immediate vs Delayed Post Space Preparation in Root Canals Filled with Bioceramic-based Root Canal Sealer
}

\author{
Paveepong Tanompetsanga ${ }^{1}$, Pakit Tungsawat ${ }^{2}$
}

\begin{abstract}
Aim: The objective of this study was to compare the microleakage rate between immediate and delayed post space preparation in the root canal filled with the bioceramic-based root canal sealer by the fluid filtration technique.

Material and methods: Sixty extracted human mandibular premolars were used. The coronal portion was resected $12 \mathrm{~mm}$ from the apex, and the root canal was prepared with Mtwo NiTi rotary instruments to apical size 50/0.04 and filled with a matched-taper gutta-percha impregnated with bioceramic particles and a bioceramic-based root canal sealer. The samples were divided into two experimental groups $(n=50)$ and two groups of positive $(n=5)$ and negative control groups $(n=5)$. Twenty-five roots of the immediate post space preparation group were prepared post space immediately following completion of root canal obturation and 25 roots of delayed post space preparation group were kept for 7 days before preparation of the post space. Evaluation of the apical leakage was performed with a fluid filtration method under a $15 \mathrm{~cm} \mathrm{H}_{2} \mathrm{O}$ pressure. Results: There was no significant difference $(p=0.55)$ in apical microleakage between immediate and delayed post space preparation groups. Conclusion: In terms of apical microleakage, immediate and delayed post space preparation produced similar outcomes when the root canal filled with bioceramic-based root canal sealers by a single-cone technique.

Clinical significance: The timing of post space preparation does not affect the apical microleakage results when the root canal filled with bioceramic-based root canal sealers by a single-cone technique.

Keywords: Apical leakage, Bioceramic, Fluid filtration, Post space preparation.

World Journal of Dentistry (2020): 10.5005/jp-journals-10015-1720
\end{abstract}

\section{INTRODUCTION}

Post space preparation is a standard procedure for the restoration of endodontically treated teeth. The process involves removing the filling materials from the coronal portion of the root canal. The rotary and heat instrument are a standard method to eliminate the root canal filling materials. ${ }^{1}$ The Peeso reamer or Gates Glidden drill is used to prepare the size of the canal to fit the size of the post. The procedure generates heat and forces that interact with the remaining root canal filling material in the apical region can compromise the apical seal. ${ }^{2}$

Root canal filling is a necessary process to prevent recontamination of the canal that will lead to the success of the treatment. ${ }^{3,4}$ Gutta-percha point is the most common material used for root canal filling, but it does not provide an excellent seal to the canal wall. The root canal cement or sealer is required to seal the gap between each piece of the gutta-percha point and the root canal wall. The ideal root canal sealer should have several properties such as excellent adhesion with the canal wall, proper setting time, biocompatibility, bacteriostatic, insoluble in the tissue, easy removal, not stain the tooth, and sufficiently radiopaque. ${ }^{5}$ Zinc oxide eugenol-based and resin-based root canal sealers are currently used. Recently, a bioceramic-based root canal sealer is introduced for root canal obturation. TotalFill BC Sealer (FKG Dentaire SA, Switzerland) consists of tricalcium silicate, dicalcium silicate, calcium phosphates, colloidal silica, and calcium hydroxide. ${ }^{6}$ The vehicles of a premixed paste are waterfree thickening. The radiopacifying agents are zirconium oxide. The material uses the moisture within the dentinal tubules for the
${ }^{1,2}$ Department of Endodontics, College of Dental Medicine, Rangsit University, Muang Pathum Thani, Thailand

Corresponding Author: Pakit Tungsawat, Department of Endodontics, College of Dental Medicine, Rangsit University, Muang Pathum Thani, Thailand, Phone: +66-2997-2200, e-mail: pakit.tu@rsu.ac.th

How to cite this article: Tanompetsanga P, Tungsawat P. Microleakage in Immediate vs Delayed Post Space Preparation in Root Canals Filled with Bioceramic-based Root Canal Sealer. World J Dent 2020;11(3): 172-178.

Source of support: Nil

Conflict of interest: None

complete setting reaction. The setting time is 4 hours. The $\mathrm{pH}$ of the sealer is higher than 12 due to calcium hydroxide produced during the setting reaction, which provides the antibacterial activity. ${ }^{7}$ The significant advantages associated with the use of bioceramic materials as root canal sealers are hydrophilic, biocompatible, bond with the dentin wall, high alkalinity, and osteoconduction. 8,9

The effect of the post space preparation procedure on the sealing ability of the remaining root canal filling is controversial. The classic study generally states that the timing of the post space preparation in the root canal filled with gutta-percha and zinc oxide eugenol-based sealer does not affect the sealing ability, ${ }_{1}^{10,11}$ whereas a more recent article showed that immediate post space preparation was better than delayed preparation. ${ }^{12}$ Another study revealed the root canal was filled with gutta-percha and resin-based 
sealer showed no difference in sealing ability. ${ }^{13}$ Bioceramic-based root canal sealer is a new material with unique properties. Know how the timing of post space preparation affects the sealing ability of the remaining part of materials is essential to choose the proper time for performing the treatment.

The purpose of this study is to compare the effect of immediate and delayed post space preparation to the microleakage rate in the root canal filled with bioceramic-based sealer by the fluid filtration technique.

\section{Materials and Methods}

\section{Sample}

Sixty human mandibular premolars with single straight root canals extracted for the orthodontic purpose were used for the study. Samples were soaked in $0.1 \%$ thymol solution immediately. Teeth were cleaned with curettes and radiographs were made in mesiodistal and buccolingual views to confirm a straight, round single root canal without any calcification, and the difference of canal width on both views at a one-third apical level should not exceed $1 \mathrm{~mm}$.

The coronal portion of samples was cut with a carborundum disk under water spray $12 \mathrm{~mm}$ from the apex (Fig. 1A). A \#10 k-file was inserted of each root canal through the apical foramen to confirm the patency of the root canal. The tip of \#10- or \#15-k-files must be fit at the apical part of the canal. The sample was rejected if it did not fit the criteria. The canal length was determined by inserting a \#10 K-file into the canal until the tip was observed at the apical foramen (Fig. 1B). The working length was $1 \mathrm{~mm}$ short of the canal length. The root canal was prepared using the Mtwo rotary system from size 10/0.04 to 50/0.04 (Fig. 1C). An amount of $5 \mathrm{~mL}$ of $2.5 \%$ sodium hypochlorite solution was used to irrigate at every change of file. The root canal was finally irrigated with $2 \mathrm{~mL}$ of $17 \%$ EDTA solution for 1 minute and $10 \mathrm{~mL}$ of $2.5 \%$ sodium hypochlorite solution. The five pieces of the paper point were used to dry each root canal. The samples were divided into two experimental groups and two control groups.

\section{Group I: Immediate Post space Preparation $(n=25)$}

Twenty-five root canals were filled using a greater taper guttapercha impregnated with bioceramic particles (TotalFill BC Points, FKG Dentaire SA, Switzerland) size 50/0.04 and bioceramic-based root canal sealer (TotalFill BC Sealer, FKG Dentaire SA, Switzerland). According to manufacturer's instructions, the tip of the $B C$ sealer syringe was inserted into the coronal one-third of the root canal (Fig. 2A). The sealer was gently and smoothly dispensed into the root canal. The amount of sealer used to fill each canal was controlled by compressing the plunger of the syringe for one volume calibration mark per canal (Fig. 2B). The canal walls were lightly coated with the existing sealer in the canal using a \#15 k-file. The master guttapercha cone was cut a notch by surgical blade no. 15 at $4 \mathrm{~mm}$ from the tip (Fig. 2C). The depth of incision was a radius of the guttapercha cone. Then the gutta-percha cone was coated with a thin layer of sealer and slowly inserted into the canal. The post space was immediately prepared by twisting the gutta-percha cone until it was separated from the tip, and then the remaining root canal filling was vertical condensed by using an endodontic plugger with a $1.0 \mathrm{~mm}$ diameter at the working end. The Peeso reamers were used to prepare the root canal to size 3 . The sample was kept in a container of $95 \%$ relative humidity at room temperature for 7 days. The samples were radiographed to confirm a 4-mm root canal filling in the apical part of the root canal.

\section{Group II: Delayed Post space Preparation $(n=25)$}

Twenty-five root canals were filled using a greater taper guttapercha impregnated with bioceramic particles (TotalFill BC Points, FKG Dentaire SA, Switzerland) of size 50/0.04 and bioceramic-based root canal sealer (TotalFill BC Sealer, FKG Dentaire SA, Switzerland). The tip of the $B C$ sealer syringe was inserted into the coronal one-third of the root canal. The sealer was gently and smoothly dispensed into the root canal. The amount of sealer used to fill each canal was controlled by compressing the plunger of the syringe for one volume calibration mark per canal. Using a \#15 K-file the canal walls were lightly coated with the existing sealer in the canal. Then the gutta-percha cone was coated with a thin layer of sealer and slowly inserted into the canal. The gutta-percha was cut at the coronal end and lightly compacted with a $1.0 \mathrm{~mm}$ diameter at the working end of the endodontic plugger. The sample was kept in a container of $95 \%$ relative humidity at room temperature for 7 days before the preparation of the post space. The Beefill heat plugger (Beefill system, VDW ${ }^{\circledR} \mathrm{GmbH}$, München, Germany) size $60 / 0.06$ was used to remove the gutta-percha (Fig. 2D), and then the remaining root canal filling was vertically condensed with an endodontic plugger with a $1.0 \mathrm{~mm}$ diameter at the working end (Fig. 2E). Peeso

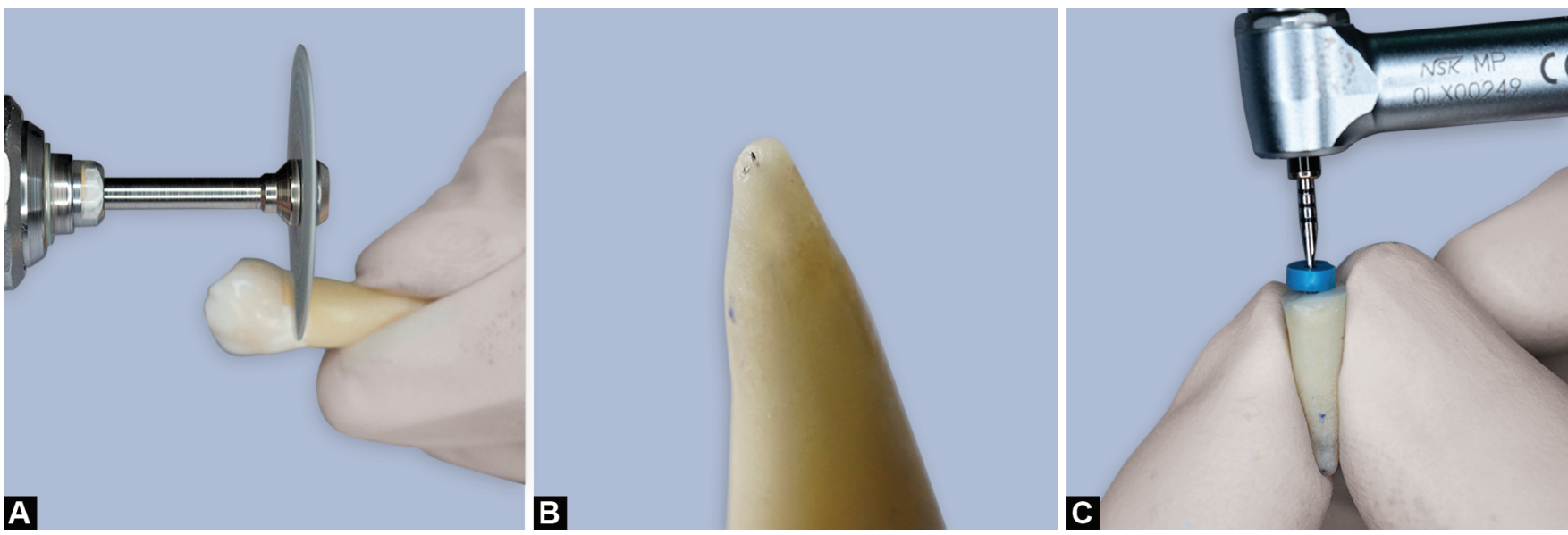

Figs 1 A to C: Tooth preparation: (A) The coronal portion of tooth was cut with a carborundum disk; (B) A \#10 K-file was inserted of each root canal through the apical foramen; (C) The root canal was prepared using the Mtwo rotary system from size 10/0.04 to 50/0.04 

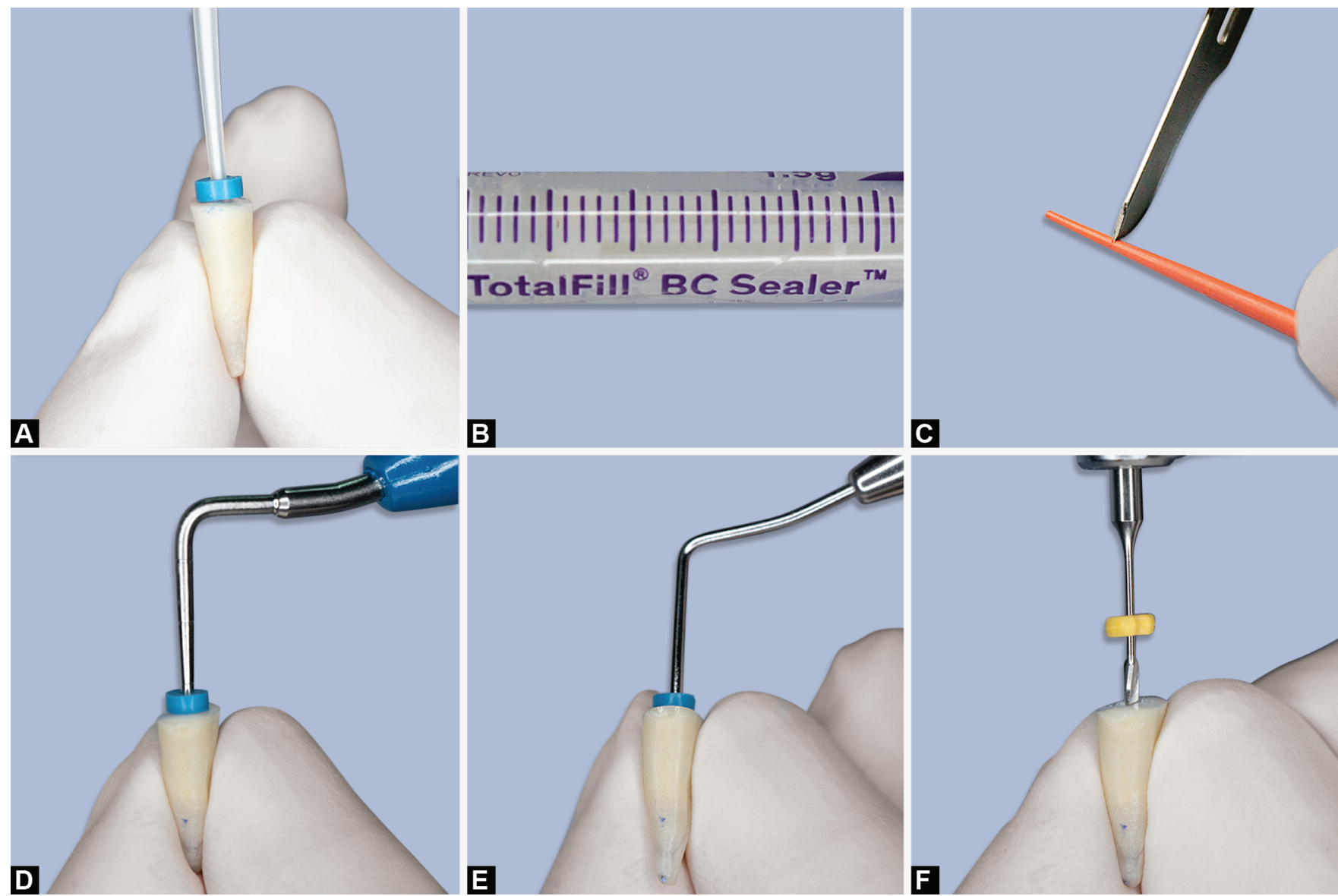

B

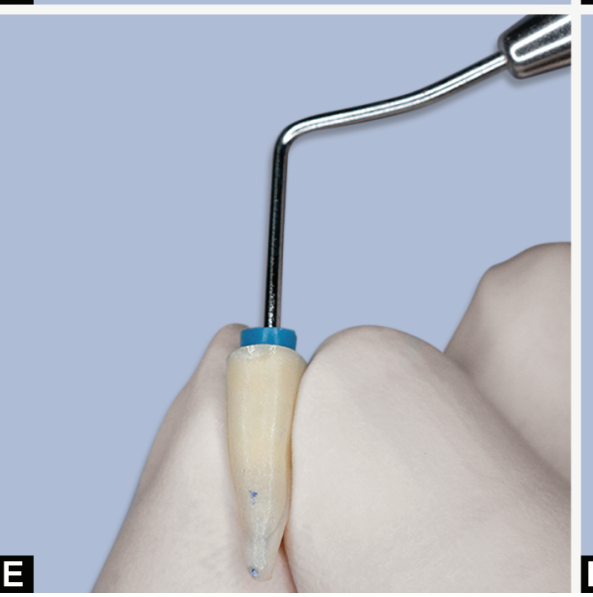

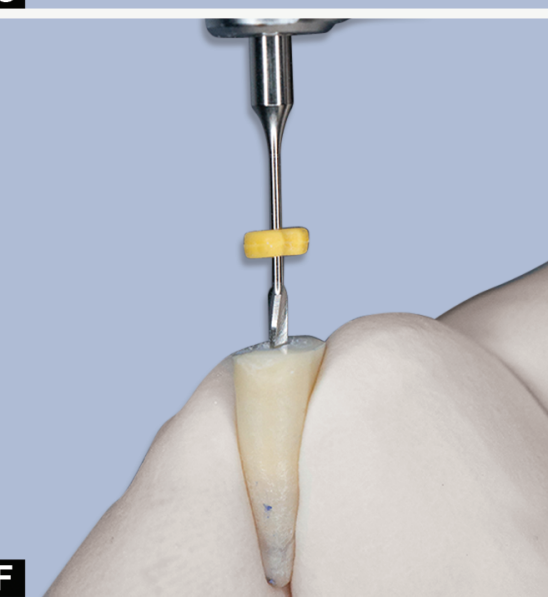

Figs $2 A$ to F: Root canal obturation and post space preparation: (A) The tip of the TotalFill BC sealer syringe was inserted into the coronal one-third of the root canal; (B) The volume calibration mark of the TotalFill BC sealer syringe; (C) The master gutta-percha cone was cut a notch by surgical blade no. 15; (D) Using Beefill heat plugger (Beefill system, VDW GmbH, München, Germany) size 60/0.06 to remove gutta-percha; (E) Vertically condensed the remaining root canal filling with an endodontic plugger; (F) Peeso Reamer was used to preparing the root canal to size 3

Reamer was used to prepare the root canal to size 3 (Fig. 2F). The samples were radiographed to confirm a $4-\mathrm{mm}$ root canal filling in the apical part of the root canal.

\section{Positive Control Group $(n=5)$}

Five roots were prepared using Mtwo rotary files to size 50/0.04 and irrigated with $5 \mathrm{~mL}$ of $2.5 \%$ sodium hypochlorite solution at each file change. After complete root canal shaping, each root canal was irrigated with $2 \mathrm{~mL}$ of a $17 \%$ EDTA solution for 1 minute and $10 \mathrm{~mL}$ of a $2.5 \%$ sodium hypochlorite, then dried with five pieces of paper points. The canals were filled with a greater taper gutta-percha cone size 50/0.04 without the use of a sealer.

\section{Negative Control Group ( $n=5)$}

Five roots were prepared in the same manner as the positive control group. Then the roots were completely covered with two layers of nail varnish, including the coronal end and apical foramen.

All samples were kept in a container of $95 \%$ relative humidity at room temperature for 7 days until microleakage evaluation.

\section{Microleakage Assessment}

The fluid filtration device was used for the measurement of microleakage as described by Wu and Wesselink (Fig. 3). ${ }^{14}$ The external root surfaces of all specimens were coated with nail varnish except for an area of $1 \mathrm{~mm}$ coronal and apical end of the root.

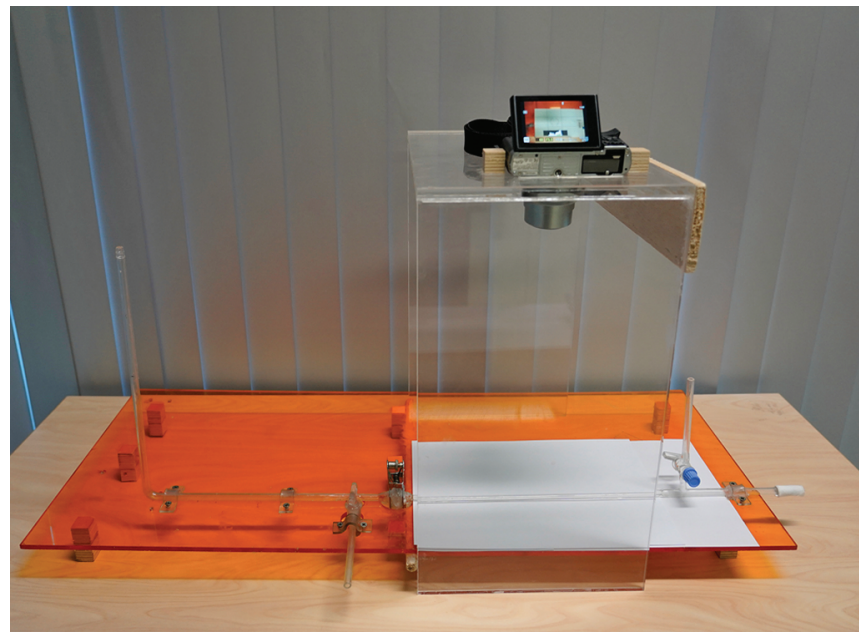

Fig. 3: Fluid filtration device and a 16-megapixel digital camera were used to record the bubble movement

The specimens were then connected to the fluid filtration device (Fig. 4A). The connection was sealed with cyanoacrylate glue and multiple layers of silicone sealant (Neobond) to obtain a closed system. Any possible leakage in the system was tested by using a tissue paper wrap around the connecting joint between the sample 

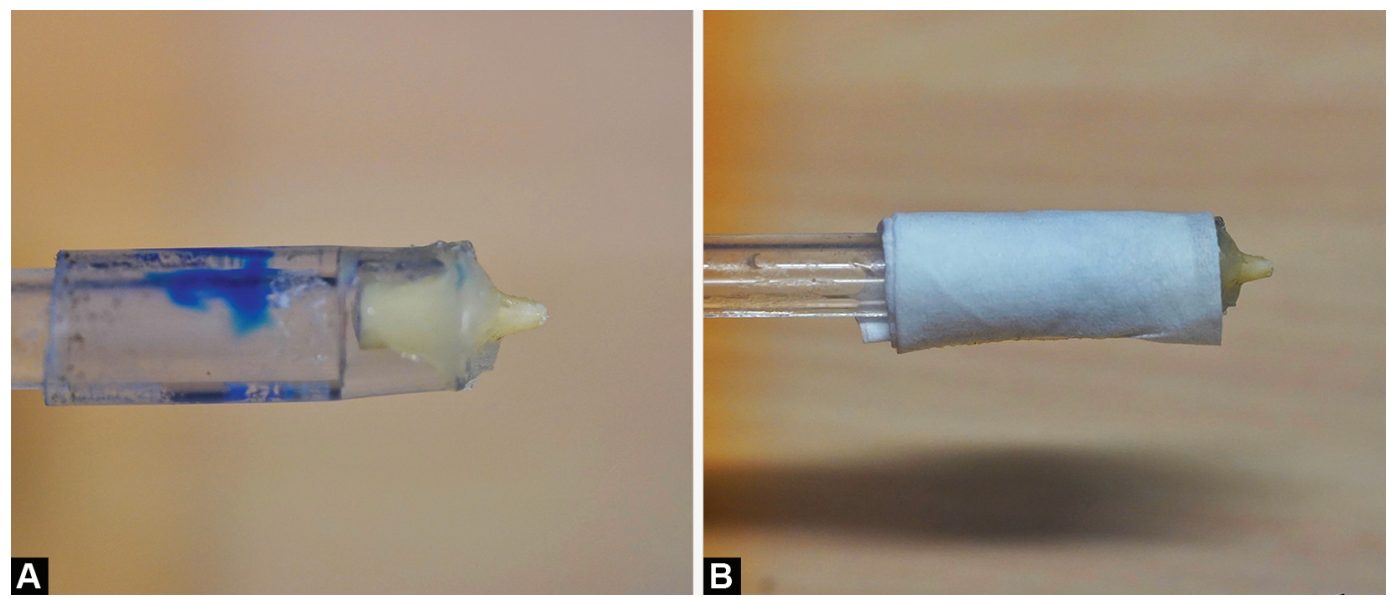

Figs 4A and B: Connecting the sample to the fluid filtration device: (A) The connection was sealed with cyanoacrylate glue and multiple layers of silicone sealant; (B) Tissue paper wraps around the connecting joint between the sample and the device to check for a leak in systems

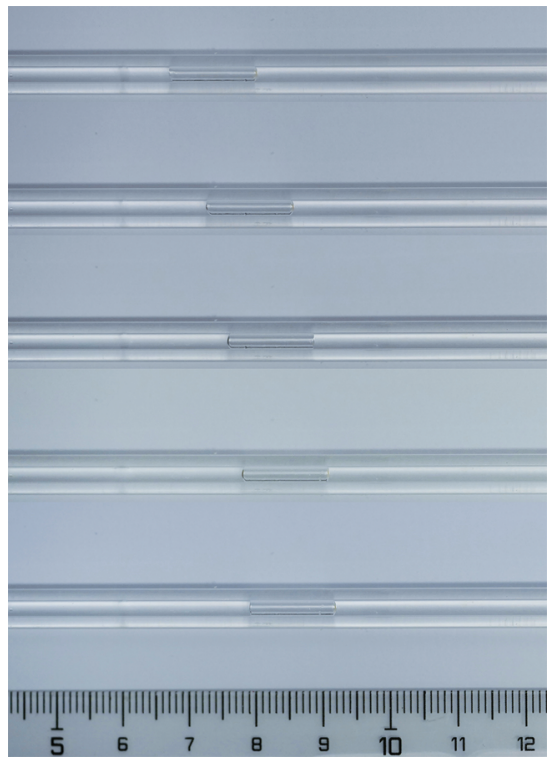

Fig. 5: The displacement of the air bubble in a 1-mm-diameter micropipette

and the device (Fig. 4B). If the tissue paper got wet that indicate the leakage of the system; the sample was reattached to the device. Leakage was evaluated by the fluid filtration method employing a pressure equivalent to $15 \mathrm{~cm} \mathrm{H}_{2} \mathrm{O}$. The passage of liquid through the samples was assessed by the measurement of bubble displacement. A 16-megapixel digital camera (Olympus OM-D-E-M10) and ImageJ program version $1.51 \mathrm{j} 8$ were used to record and analyze the bubble movement (Fig. 5). Measurements of bubble movement were made at 15-minute intervals for 3 hours. The data began recording after the tissue paper had dried for 30 minutes, and the tissue paper must dry throughout the leakage test.

Five roots of positive control and five roots of negative control groups were tested before evaluating the microleakage of the experimental groups.

The Image J program version 1.51j8 (National Institute of Health, USA) was used to measure bubble displacement of each sample in millimeters and calculate the microleakage rate using the following formula:

$$
v=\frac{\pi r^{2} l}{p \cdot t}
$$

$v=$ infiltration rate $\left(\mathrm{nL} / \mathrm{cm} \mathrm{H}_{2} \mathrm{O}\right.$ minute)

$I=$ length of air bubble movement $(\mathrm{mm})$

$r=$ internal diameter of micropipette $(\mathrm{mm})$

$p=$ pressure $\left(\mathrm{cm} \mathrm{H}_{2} \mathrm{O}\right)$

$t=$ time (minute)

\section{Statistical Analysis}

The data were analyzed using SPSS 24.0 for Windows (SPSS Inc., Chicago, IL). The average and standard deviation of the microleakage rate for each group were calculated. The data analysis would be performed by an independent Student's $t$ test. All statistical analyzes were set at a significance level of 0.05 .

\section{RESULTS}

In the control groups, the leakage of the negative control was no evidence. The bubble did not move throughout the 3 hours of microleakage assessment. The leakage of the positive control could not be recorded because the bubble had rushed through the capillary of the fluid filtration device for less than 15 minutes.

The microleakage rate of each specimen in the experimental groups is presented in Table 1. The mean and the standard deviation of both groups are shown in Table 2 . In the immediate group, the microleakage rate was $2.67 \mathrm{~nL} / \mathrm{cm} \mathrm{H}_{2} \mathrm{O}$ minute, and the standard deviation was 1.55. In the delayed group, the microleakage rate was $2.46 \mathrm{~nL} / \mathrm{cm} \mathrm{H}_{2} \mathrm{O}$ minute, and the standard deviation was 0.83 . The distribution of the microleakage rate of delayed and immediate post space preparation groups is presented in Figure 6. The statistical analysis showed that the microleakage rate of each group was normally distributed, as present in Table 3 . The independent Student's $t$ test was used for comparing the microleakage rate between the immediate and delayed groups, as present in Table 4. There was no statistical difference ( $p$ value $=0.55$ ).

\section{Discussion}

There are various methods for evaluating microleakage in endodontics, such as the dye penetration test, the bacterial leakage 
Table 1: The microleakage rate of each specimen

\begin{tabular}{|c|c|c|}
\hline $\begin{array}{l}\text { Number of } \\
\text { specimen }\end{array}$ & Group & $\begin{array}{l}\text { Microleakage rate } \\
\text { (nL/cm } \mathrm{H}_{2} \mathrm{O} \text { minute) }\end{array}$ \\
\hline 1 & Immediate group & 1.01 \\
\hline 2 & Immediate group & 5.47 \\
\hline 3 & Immediate group & 3.24 \\
\hline 4 & Immediate group & 1.23 \\
\hline 5 & Immediate group & 4.21 \\
\hline 6 & Immediate group & 5.76 \\
\hline 7 & Immediate group & 1.22 \\
\hline 8 & Immediate group & 0.53 \\
\hline 9 & Immediate group & 1.99 \\
\hline 10 & Immediate group & 4.52 \\
\hline 11 & Immediate group & 3.38 \\
\hline 12 & Immediate group & 3.27 \\
\hline 13 & Immediate group & 2.96 \\
\hline 14 & Immediate group & 1.22 \\
\hline 15 & Immediate group & 1.64 \\
\hline 16 & Immediate group & 4.57 \\
\hline 17 & Immediate group & 2.19 \\
\hline 18 & Immediate group & 2.60 \\
\hline 19 & Immediate group & 1.18 \\
\hline 20 & Immediate group & 3.68 \\
\hline 21 & Immediate group & 0.65 \\
\hline 22 & Immediate group & 1.94 \\
\hline 23 & Immediate group & 1.91 \\
\hline 24 & Immediate group & 4.80 \\
\hline 25 & Immediate group & 1.64 \\
\hline 26 & Delayed group & 2.12 \\
\hline 27 & Delayed group & 1.99 \\
\hline 28 & Delayed group & 2.85 \\
\hline 29 & Delayed group & 2.45 \\
\hline 30 & Delayed group & 1.67 \\
\hline 31 & Delayed group & 2.88 \\
\hline 32 & Delayed group & 1.80 \\
\hline 33 & Delayed group & 2.66 \\
\hline 34 & Delayed group & 1.86 \\
\hline 35 & Delayed group & 2.74 \\
\hline 36 & Delayed group & 1.85 \\
\hline 37 & Delayed group & 5.20 \\
\hline 38 & Delayed group & 2.97 \\
\hline 39 & Delayed group & 1.89 \\
\hline 40 & Delayed group & 3.22 \\
\hline 41 & Delayed group & 1.26 \\
\hline 42 & Delayed group & 1.87 \\
\hline 43 & Delayed group & 0.90 \\
\hline 44 & Delayed group & 2.55 \\
\hline 45 & Delayed group & 2.52 \\
\hline 46 & Delayed group & 2.76 \\
\hline 47 & Delayed group & 2.89 \\
\hline 48 & Delayed group & 2.74 \\
\hline 49 & Delayed group & 2.68 \\
\hline 50 & Delayed group & 3.21 \\
\hline
\end{tabular}

Table 2: Descriptive statistics of microleakage rate between immediate and delayed post space preparation groups

\begin{tabular}{llll}
\hline Group & $n$ & $\begin{array}{l}\text { Mean }(\mathrm{nL} / \mathrm{cm} \\
\left.\mathrm{H}_{2} \mathrm{O} \text { minute }\right)\end{array}$ & $\begin{array}{l}\text { Standard } \\
\text { deviation }\end{array}$ \\
\hline Immediate group & 25 & 2.67 & 1.55 \\
Delayed group & 25 & 2.46 & 0.83 \\
\hline
\end{tabular}

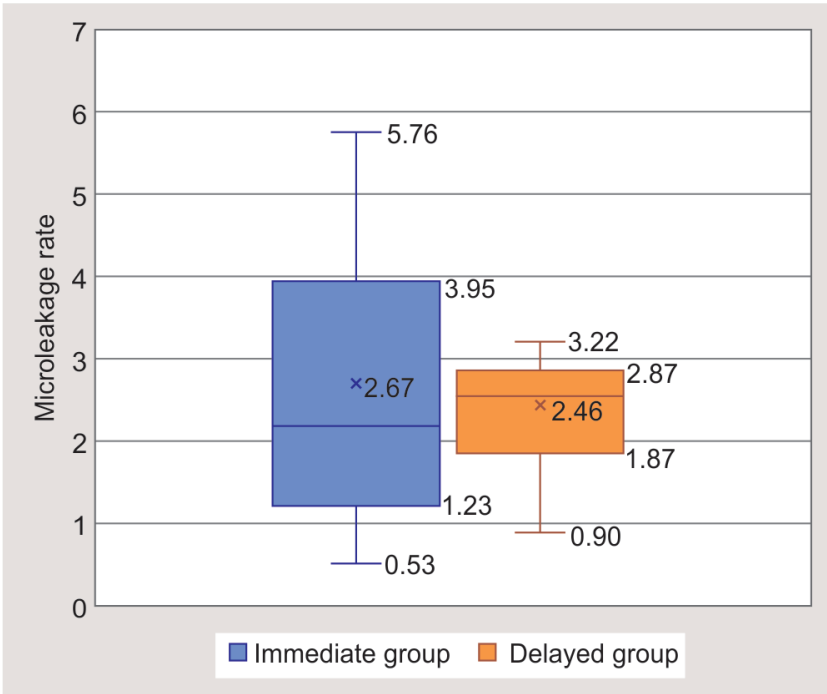

Fig. 6: The box plots display the distribution of the microleakage rate between immediate and delayed post space preparation groups

Table 3: Normality test of microleakage rate between immediate and delayed post space preparation groups

\begin{tabular}{llll}
\hline & & \multicolumn{2}{c}{ Kolmogorov-Smirnov test } \\
\cline { 3 - 4 } Group & $n$ & Statistic & Sig. \\
\hline Immediate group & 25 & 0.150 & 0.148 \\
Delayed group & 25 & 0.149 & 0.154 \\
\hline
\end{tabular}

test, the saliva leakage test, the glucose leakage test, and the fluid filtration test. In this study, we use the fluid filtration method to evaluate the apical leakage of the samples because there were many advantages such as the samples were not destroyed, the results were quantitative and highly sensitive, and there were no chemical reactions with the samples. ${ }^{15}$

Although the fluid filtration test is considered to be a highly sensitive method for evaluating apical microleakage, this method could not detect a significant difference in the apical leakage rate due to a minimal effect size. From the results of this study, it was presented that the effect size was 0.17 , which is classified as small $(d<0.2)$ according to the Cohen's effect size index. ${ }^{16}$

The current study used $1 \mathrm{~cm}$ of bubble size and $1 \mathrm{~mm}$ of the inner diameter of the micropipette. The pressure and measurement time were $15 \mathrm{~cm} \mathrm{H}_{2} \mathrm{O}$ and 3 hours, respectively. According to the previous study, the pressure, the bubble size, and the inner diameter of the micropipette could affect the system sensitivity. ${ }^{17}$ A pressure of $15 \mathrm{~cm} \mathrm{H}_{2} \mathrm{O}$, as it was close to physiologic pressure, would be sufficiently sensitive to detect the difference of microleakage between the experimental groups.

From the result of this study, there was no significant difference between the leakage rate of the immediate and delayed post space 
Microleakage after Immediate and Delayed Post Space Preparation

Table 4: Comparison of microleakage rate between immediate and delayed post space preparation groups with independent Student's $t$ test

\begin{tabular}{lllllll}
\hline & & & & & \multicolumn{2}{c}{$95 \%$ confidence interval of the difference } \\
\cline { 6 - 7 }$t$ & $d f$ & Sig. (two-tailed) & Mean difference & Std. error difference & Lower & Upper \\
\hline 0.602 & 48 & 0.550 & 0.2112 & 0.35097 & -0.49448 & 0.91688 \\
\hline
\end{tabular}

preparation group, which is dissimilar from previous studies that the delayed post space preparation group has less apical leakage than the immediate group significantly. ${ }^{18}$ The primary cause of disparate results is the different root canal sealer types used to fill the root canal among the studies. In this study, the bioceramic-based sealer was used whereas other studies used zinc oxide-eugenol-based, resin-based sealers such as AH plus, or MTA-based sealer. ${ }^{19}$ The bioceramic-based sealer is a calcium silicate-based sealer that has a hydrophilic property. This type of sealer utilizes moisture within the canal to complete the setting reaction, so it can fully set in a moisture environment. On the contrary, the resin-based sealer is hydrophobic; the water in the dentinal tubule could interfere with the setting reaction. Moreover, the bioceramic-based sealer does not shrink but slightly expands on setting. ${ }^{20}$

The results of the present study demonstrate that apical leakage between immediate and delayed post space preparation groups was no different, whereas the standard deviation of immediate groups was twice more than delayed groups. The statistics would seem to suggest that the apical seal after post space preparation in the delayed post space preparation group is more reliable than the immediate post space preparation group. The heat and force that were generated during post space prepare immediately after root canal obturation might cause displacement of the master gutta-percha point, ${ }_{i}^{21}$ however, the apical microleakage rate did not differ from the delayed group. The bioceramic-based sealer has an excellent flow that can refill the space created by the displacement of the master gutta-percha point. ${ }^{22}$

The post space preparation procedure generated heat and forces directly to the filling material in the root canal. In the previous study, post space preparation 1 week after the obturation of the root canal with $\mathrm{AH}$ plus using the warm vertical compaction technique has more microleakage than immediate preparation. ${ }^{23}$ The heat and force generated by drilling can break the bond in the complete set sealer that thin and brittle. ${ }^{24}$ In this study, however, the root canal was filled with bioceramic-based sealer using a single-cone technique. In contrast with another root canal obturation technique, this technique uses bioceramic-based sealer as the primary material to fill the root canal space while the gutta-percha point was used to deliver the sealer into the canal and serve as a guide for removal of the root canal filling in case of retreatment. A thick layer of sealer is durable to heat and force that were generated during the post space preparation process.

The bioceramic-based sealer displayed the highest bond with the dentin of the root canal wall. ${ }^{25}$ The powder of calcium silicates reacts with the water to form a calcium silicate hydrate gel and calcium hydroxide. Then the calcium hydroxide reacts with the phosphate ions to produce hydroxyapatite and water. The water from the previous reaction reacts with the calcium silicates to produce additional gel-like calcium silicate hydrate that precipitates into the dentinal tubule of the root canal wall. ${ }^{26,27}$ The previous types of sealers tend to shrink and early debond from the root canal wall cause of microleakage.

This study used the gutta-percha impregnated and coated with bioceramic nanoparticles as the master gutta-percha point.
The manufacturer claims that bonding between the sealer and gutta-percha point surface will reduce microleakage. ${ }^{28,29}$ According to the previous study on the bond strength between $\mathrm{BC}$ point and $\mathrm{BC}$ sealer, the bond strength will increase as time passes. ${ }^{30}$ The result of this study indicates that the time of post space preparation does not affect the bond between the guttapercha surface and the sealer.

\section{Conclusion}

In terms of apical microleakage, immediate and delayed post space preparation produced similar outcomes when the root canal was filled with bioceramic-based root canal sealers by a single-cone technique.

\section{Clinical Significance}

The timing of post space preparation does not affect the apical microleakage results when the root canal is filled with bioceramicbased root canal sealers by a single-cone technique.

\section{Authors' Contributions}

Paveepong Tanompetsanga and Pakit Tungsawat contributed in study design, data acquisition, data analysis, and drafting the manuscript. Pakit Tungsawat contributed in reviewing the manuscript.

\section{References}

1. Schwartz RS, Robbins JW. Post placement and restoration of endodontically treated teeth: a literature review. J Endod 2004;30(5):289-301. DOI: 10.1097/00004770-200405000-00001.

2. Saunders EM, Saunders WP. The heat generated on the external root surface during post space preparation. Int Endod J 1989;22(4): 169-173. DOI: 10.1111/j.1365-2591.1989.tb00919.x.

3. Ray HA, Trope M. Periapical status of endodontically treated teeth in relation to the technical quality of the root filling and the coronal restoration. Int Endod J 1995;28(1):12-18. DOI: 10.1111/j.13652591.1995.tb00150.x.

4. Kirkevang LL, Orstavik D, Horsted-Bindslev P, et al. Periapical status and quality of root fillings and coronal restorations in a Danish population. Int Endod J 2000;33(6):509-515. DOI: 10.1046/j.13652591.2000.00381.x.

5. Orstavik DAG. Materials used for root canal obturation: technical, biological and clinical testing. Endod Topics 2005;12(1):25-38. DOI: 10.1111/j.1601-1546.2005.00197.x.

6. Jafari F, Jafari S. Composition and physicochemical properties of calcium silicate-based sealers: a review article. J Clin Exp Dent 2017;9(10):e1249-e1255. DOI: 10.4317/jced.54103.

7. Zhou H-M, Shen Y, Zheng W, et al. Physical properties of 5 root canal sealers. J Endod 2013;39(10):1281-1286. DOI: 10.1016/j. joen.2013.06.012.

8. Mestieri LB, Gomes-Cornélio AL, Rodrigues EM. Biocompatibility and bioactivity of calcium silicate-based endodontic sealers in human dental pulp cells. J Appl Oral Sci 2015;23(5):467-471. DOI: 10.1590/1678-775720150170.

9. Camps J, Jeanneau C, El Ayachi I, et al. Bioactivity of a calcium silicatebased endodontic cement (BioRoot RCS): Interactions with human 
periodontal ligament cells in vitro. J Endod 2015;41(9):1469-1473. DOI: 10.1016/j.joen.2015.04.011.

10. Mattison GD, Delivanis PD, Thacker RW, Jr, et al. Effect of post preparation on the apical seal. J Prosthet Dent 1984;51(6):785-789. DOI: 10.1016/0022-3913(84)90377-9.

11. Camp LR, Todd MJ. The effect of dowel preparation on the apical seal of three common obturation techniques. J Prosthet Dent 1983;50(5):664-666. DOI: 10.1016/0022-3913(83) 90206-8.

12. Fan B, Wu M-K, Wesselink PR. Coronal leakage along apical root fillings after immediate and delayed post space preparation. Endod Dent Traumatol 1999;15(3):124-126. DOI: 10.1111/j.1600-9657.1999. tb00768.x.

13. Abramovitz I, Tagger M, Tamse A, et al. The effect of immediate vs. delayed post space preparation on the apical seal of a root canal filling: A study in an increased-sensitivity pressure-driven system. J Endod 2000;26(8):435-439. DOI: 10.1097/00004770-20000800000001.

14. Wu MK, De Gee AJ, Wesselink PR. Fluid transport and dye penetration along root canal fillings. Int Endod J 1994;27(5):233-238. DOI: 10.1111/j.1365-2591.1994.tb00261.x.

15. Javidi M, Naghavi N, Roohani E. Assembling of fluid filtration system for quantitative evaluation of microleakage in dental materials. Iran Endod J 2008;3(3):68-72.

16. Sullivan GM, Feinn R. Using effect size-or why the $p$ value is not enough. J Grad Med Educ 2012;4(3):279-282. DOI: 10.4300/JGME-D12-00156.1.

17. Pommel L, Camps J. Effects of pressure and measurement time on the fluid filtration method in endodontics. J Endod 2001;27(4):256-258. DOI: 10.1097/00004770-200104000-00003.

18. Bodrumlu E, Tunga U, Alacam T. Influence of immediate and delayed post space preparation on sealing ability of resilon. Oral Surg Oral Med Oral Pathol Oral Radiol Endod 2007;103(6):e61-e64. DOI: 10.1016/j.tripleo.2006.12.013.

19. Dhaded N, Uppin VM, Dhaded S, et al. Evaluation of immediate and delayed post space preparation on sealing ability of resilon-epiphany and gutta percha-AH plus sealer. J Conserv Dent 2013;16(6):514-517. DOI: $10.4103 / 0972-0707.120962$.
20. Silva Almeida LH, Moraes RR, Morgental RD, et al. Are premixed calcium silicate-based endodontic sealers comparable to conventional materials? A systematic review of in vitro studies. J Endod 2017;43(4):527-535. DOI: 10.1016/j.joen.2016.11.019.

21. Gokturk H, Ozkocak I, Taskan MM, et al. In vitro evaluation of temperature rise during different post space preparations. Eur J Dent 2015;9(4):535-541. DOI: 10.4103/1305-7456.172630.

22. Candeiro GTDM, Correia FC, Duarte MAH, et al. Evaluation of radiopacity, $\mathrm{pH}$, release of calcium ions, and flow of a bioceramic root canal sealer. J Endod 2012;38(6):842-845. DOI: 10.1016/ j.joen.2012.02.029.

23. Padmanabhan P, Das J, Kumari RV, et al. Comparative evaluation of apical microleakage in immediate and delayed post space preparation using four different root canal sealers: An in vitro study. J Conserv Dent 2017;20(2):86-90. DOI: 10.4103/0972-0707.212230.

24. Dhaded N, Dhaded S, Patil C, et al. The effect of time of post space preparation on the seal and adaptation of resilon-epiphany se \& gutta-percha-AH plus sealer - an SEM study. J Clin Diag Res 2014;8(1):217-220. DOI: 10.7860/JCDR/2014/6787.3955.

25. Nagas E, Uyanik MO, Eymirli A, et al. Dentin moisture conditions affect the adhesion of root canal sealers. J Endod 2012;38(2):240-244. DOI: 10.1016/j.joen.2011.09.027.

26. Sarkar NK, Caicedo R, Ritwik P, et al. Physicochemical basis of the biologic properties of mineral trioxide aggregate. J Endod 2005;31(2):97-100. DOI: 10.1097/01.don.0000133155.04468.41.

27. Bozeman TB, Lemon RR, Eleazer PD. Elemental analysis of crystal precipitate from gray and white MTA. J Endod 2006;32(5):425-428. DOI: 10.1016/j.joen.2005.08.009.

28. Debelian G, Trope M. The use of premixed bioceramic materials in endodontics. Giorn Ital Endod 2016;30(2):70-80. DOI: 10.1016/ j.gien.2016.09.001.

29. Hegde V, Arora S. Sealing ability of three hydrophilic single cone obturation systems: An in vitro glucose leakage study. Contemp Clin Dent 2015;6(Suppl 1):S86-S89. DOI: 10.4103/0976-237X.152953.

30. Yap WY, Che Ab Aziz ZA, Azami NH, et al. An in vitro comparison of bond strength of different sealers/obturation systems to root dentin using the push-out test at 2 weeks and 3 months after obturation. Med Princ Pract 2017;26(5):464-469. DOI: 10.1159/000481623. 